\title{
EVALUATION OF PSYCHOMETRIC PROPERTIES OF THE STATE AND TRAIT ANXIETY INVENTORY SCALE IN A STUDENT SAMPLE
}

\author{
Aivars Kaupuzs \\ Rezeknes Augstskola, Latvia \\ Zermena Vazne \\ Latvian Academy of Sport Education, Latvia \\ Svetlana Usca \\ Rezeknes Augstskola, Latvia
}

\begin{abstract}
Problems with anxiety are one of the most common presenting problems for university students that affect the mental health. A sample of students (total $n=318$ ) were administered Spielberger's State and Trait Anxiety Scale. The demographics of the participants included 38.4\% $(n=122)$ males and $61.6 \%(n=196)$ females, participants ranged in ages from 18 to 25 years old. The average age of respondents was 20.92 $(S D=2.07)$. This study was conducted to evaluate of psychometric properties of the Spielberger's State-Trait Anxiety Inventory form in a student sample. The internal consistency for the STAI was calculated by Cronbach alpha coefficient $(\alpha=0,809)$. Principal component analysis with Varimax rotation was performed to assess the factor structure for the total sample that yielded four factors. Descriptive statistics were also calculated for the sample. They were found to be moderately trait anxious $(M=38.89, S D=8.92)$ with lower state anxiety $(M=35.79, S D=9.80)$. The findings of this study suggest that the scale was shown to be reliable and may be valid for measuring anxiety in a student sample.
\end{abstract}

Keywords: factor analysis; psychometric properties; strait-trait anxiety inventory; students.

\section{Introduction}

Anxiety and stress are among the most important factors that have been studied within the framework of the science of psychology. Anxiety can be defined as an unpleasant mood or emotion described as uncertainty. That mental state can be caused by an unknown or non-specific source, and concerned about the future (Tyrer, 1999). There are different types of anxiety disorders: social anxiety disorder, panic disorder or specific phobias. Some anxiety level is a normal person emotional state that can be experienced when faced with a problem at work, before taking a test, or making an important decision. The scientific literature is noted that one of the main causes of mental disorders has increased the anxiety level (Stein \& Stein, 2008). The beginning of the study is related to the major changes that are caused by stressful situations and psychological pressure among young people. Students have to adapt to the new demands, whether it be their new responsibilities, unusual environment, different style of teaching or changes of social status. That may be main factors of raising the anxiety level. Early diagnosis of the problem and providing 
support activities will contribute to the students' adaptation to their new social environment.

The aim of this study was to investigate psychometric properties, such as factorial analysis and mean values, of the Latvian version of the trait form STAI in a student sample.

\section{Research design and methods}

The study is based on Spielberger and colleagues developed the State-Trait Anxiety Inventory form. That is valid self-reported anxiety measures and it is worldwide used scale. Anxiety as a personality trait is characterized by a status or acquired behavioral dispositions that provide individuals to perceive a wide range of objectively safe objects as a threat-based. It causes the increasing the state anxiety that intensity is not adequate to objective danger level. In other words the scale measures the intensity of how much anxiety a person feels "right now" (state anxiety STAI-S) and the frequency of how often a person generally feels anxious (trait anxiety STAI-T) (Spilberger, 1985).

Spielberg scale is developed in students sample research and demonstrate excellent psychometric properties by comparing with other instruments such as the Taylor Manifest Anxiety Scale and the Anxiety Scale Questionnaire. Evidence of concurrent validity of these scales with the STAI has been found to range from .70 to .85 . (Spielberger, 1985).

This indicates that STAI scale can be applicable to determine the level of anxiety in students' sample.

The Latvian version of the STAI was used in this research that was validated and standardized by Shkushkovnika in 2004 (Škuškovnika, 2004).

The STAI consists of two self-report scales that measure state (STAI-S) and trait anxiety (STAI-T). Participants are asked to read the statements, and then circle the number to the right of the statement to indicate. Choices included $1=$ not at all; $2=$ somewhat; $3=$ moderately so; and $4=$ very much so. The STAI-S items contain statements of how people feel at the current moment "right now". The STAI-T items statements of how they feel generally. Each scale has twenty statements such as: „I feel safe” (STAY-S) and „I worry too much over something that really doesn't matter" (STAY-T). Choices included $1=$ almost never; $2=$ sometimes; $3=$ often; and $4=$ almost always. Spielberger (1983) reports that the scale can vary from a minimum of 20 to a maximum of 80 , with those reporting higher scores exhibiting more self-reported symptoms of anxiety.

The study subjects were students of Rezekne Augstskola and Latvian Academy of Sport Education. The demographics of the participants included $38.4 \%(\mathrm{n}=122)$ males and 61.6\% $(\mathrm{n}=196)$ females, for a total of 318 participants. Participants ranged in ages from 18 years old to 25 years old. The average age of respondents was $20.92(\mathrm{SD}=2.07)$ 


\section{Results}

In his study, the Cronbach's alpha coefficient was .809 that confirms the high internal consistency of the scale. Analyzing the differences between genders, it was used the Mann-Whitney and Wilcoxon criteria. The study reveals statistically significant differences between female and male data in some statements. Analyzing situational anxiety indicators, it was found that there is a statistically significant difference in irritability, anxiety and subjective self-perception. Women are less than men experiencing irritability in stressful situations $(p<.005)$ whereas men are less worried $(p<.005)$. While women under stress situations much more than men, it is important to feel pleasant $(p<.005)$.There were found two statistically significant differences between the statements that describe anxiety as personality traits. First of all, men less than women are worried about the things that really are not important $(\mathrm{p}<.005)$, while women unimportant thought comes to mind and worry about that more than it is for men $(\mathrm{p}<.005)$.

The factor analysis was conducted as the main component of the examination of the validity of students' anxiety study. In order to assess the suitability of data for factor analysis, Bartlett's test for sphericity and Kaiser Meyer-Olkin (KMO) test for sampling adequacy were carried out for STAI-S and STAI-T scales.

Table 1. The conformity of the research group for factorial analysis according KMO and Bartlett's Test (STAY-S, n=318)

\begin{tabular}{ll}
\hline Kaiser-Meyer-Olkin Measure of Sampling Adequacy & .875 \\
\hline Bartlett's Test of Sphericity. Approx. Chi-Square & 2226.552 \\
\hline df & 190 \\
\hline Sig. & .000 \\
\hline
\end{tabular}

Analyzing STAY-S results provided by respondents, was founded that according to the obtained KMO criterion value the study sample has a good correspondence for factorial analysis as Kaiser Meyer-Olkin criterion value is greater than $0.7 \quad(0.875>0.7)$. With Bartlett's criteria was checked the correspondence of observations for factor analysis. The significance level of obtained data is less than 0.05 so study sample results correspond for factor analysis $(\mathrm{p}<0.05)$ (Table 1$)$.

Extraction of factors was based on the screen plot, where only 4 components (Component Number) have greater angle and Eigenvalue greater than one (1.0) that confirming the four factor structure.

Principal component analysis with Varimax Kaiser Normalization rotation was used to determine the main factors. Factor structure was obtained after the seventh rotation.

With the first factor significant positively correlated nine STAY-S components. The first component of the content consists of 9 parts with weight 
of the factors above 0.6. The items: security $=.875$; stable $=853$, comfortable $=.822 ;$ calm $=.799$, pleasant $=.744 ;$ content $=.736$; satisfied $=.704$, self-confident $=.669$; relaxed $=.657$ were consolidated as the , inner comfort" factor.

The second factor combine five STAY-S statements which have tide positive correlation. The second factor content consists of four components with a weight above 0.6 . The items: upset $=.746$; worried $=.711$, worry about possible misfortune $=.660$; indecisive $=.642$ and one component - 'scared' $(.525)$ was aggregated as , cognitive interpretation” factor.

With the third factor significantly positively correlated four STAY-S components. The third component consists of 4 statements with a weight factor above 0.6 (tense $=.726$; strained $=.726$; nervous $=.671$; jittery $=.659$ ) and this factor is called the , internal discomfort" factor.

The fourth factor includes one statement "I feel at ease" (.643) and this factor was named as "subjective perception of easiness" factor.One component of STAI-S scale - „confused" does not correlate with any factor. Thereby the analysis of the STAI-S structure distinguishes four factors: inner comfort, cognitive interpretation, internal discomfort and subjective perception of easiness $(\mathrm{n}=318)$.

Analyzing STAY-T results provided by respondents, was founded that according to the obtained $\mathrm{KMO}$ criterion value $(0.885>0.7)$ the study sample has a good correspondence for factorial analysis. The Bartlett's criteria significance level of obtained data is less than 0.05 so study sample results correspond for factor analysis $(\mathrm{p}<0.05)$ (Table 2). Principal component analysis with Varimax Kaiser Normalization rotation was used to distinguish the main factors. Factor structure was obtained after the fifth rotation.

Table 2. The conformity of the research group for factorial analysis according KMO and Bartlett's Test (STAY-T, $n=318$ )

\begin{tabular}{ll}
\hline Kaiser-Meyer-Olkin Measure of Sampling Adequacy & .885 \\
\hline Bartlett's Test of Sphericity. Approx. Chi-Square & 1749.745 \\
\hline df & 190 \\
\hline Sig. & .000 \\
\hline
\end{tabular}

With the first factor strongly positively correlated seven STAY-T components. The first component of the content consists of 7 statements with weight above 0.6. The items: feel secure $=.815$; feel pleasant $=.804$; I am happy $=.804$; content $=.790 ;$ satisfied $=.782$; steady $=.745$; calm and cool $=.654$ were consolidated as , inner harmony” factor.

The second factor aggregate eight positively correlated STAY-T components. The content of the second factor consists of six components with a weight factor above 0.6 (unimportant thoughts $=.794$; disturbing thoughts $=.734 ;$ state of tension over concerns $=.684$; worry about 
unimportant $=.621$; I cannot forget the bitterness $=.620$; difficulties are piling up $=.610$ ) and two components with a weight factor below 0.6 (nervous $=.583$; lack of self-confidence $=.582$ ), and this factor was named ,cognitive selfconcept".

The third factor includes one statement "I feel rested" (.732) and this factor was named as the ,rest" factor.

Also the fourth factor includes one statement "I wish I could be as happy as others seem to be" (.902) and this factor was named "feelings of happiness" factor.

Three statements of STAI-T scale (make decisions easily, feel like failure, feel inadequate) do not correlate with any factor $(\mathrm{n}=318)$.

Thereby the analysis of the STAI-T structure also distinguishes four factors: inner harmony, cognitive self-concept, feelings of happiness and rest.

\section{Discussion}

Many researches reveal that the beginning of study in university or college may be the reason for an increasing of the anxiety level (Aktekin et al., 2001; Bouteyre, Maurel, \& Bernand, 2007; Mundia, 2010). Students usually have raised level of anxiety compared to other age groups, and it is found in a number of studies around the world (Wong et al., 2006). Wong and colleagues founded that students have increased anxiety level is $41 \%$ of cases, high level of stress $27 \%$ and depression $21 \%$ of the respondents.

In Sweden, Karolinska University Institute of Medicine study was founded that $12 \%$ of students have anxiety or depression that significantly affects the general health (Dahlin, Joneborg, \& Runeson, 2005). In USA Internet-based questionnaire revealed that $15.5 \%$ of students have depression or anxiety symptoms. This can be affected by many factors such as: shyness (Leary1991), lack of time, new daily tasks (Bouteyre et al., 2007) unusual environment, repeated failures of studies, financial difficulties and public presentations (Head \& Lindsey, 1983).

Peden and colleagues found out that 35 percent of female students have high levels of depression (Paden at al., 2000). Several studies reveal that women have higher anxiety level than men (Bekker \& van Mens-Verhulst, 2007).

The researches among student population points that anxiety is increased and it is more often for women (Mundia, 2010). The results of study using the STAI scale in USA university showed that male students anxiety level is lower $(M=39.48)$ than women $(M=40.78)$. In this research for total 132 respondents sample the average anxiety level was 40.25 points $(\mathrm{SD}=12.05)$ (McKnight \& McKnight, 2012). Another study data in USA university shows that students from Europe has increased the anxiety level $(\mathrm{M}=40.02, \mathrm{SD}=11.10)$. Spielberg founded that for college students' male (full-time) STAI-S mean anxiety level is 
36.47 points $(\mathrm{SD}=10.02)$ and respectively 38.76 points $(\mathrm{SD}=11.95)$ for females (Spielberg, 1983).

Our study findings partly concord with the above mentioned data because average score of STAY-S for men was 35.42 and STAY-T 38.31points, but for women respectively 36.02 and 39.25 points. It indicates the tendency that students in Latvia have lower anxiety level.

There are some carried out studies of STAY factorial analysis. Those studies distinguish two factors. The first factor reflected mainly the mood dimension, while the other one was closely connected with emotions or cognitive aspects of anxiety (Andrade et al., 2001). Also Bieling and colleagues study reveals two factors that were associated with depressive and anxiety expression (Bieling et al., 1998). However, we believe that the four-factor selection and analysis allows better determine numerous aspects of the anxiety.

This study has some limitations. Our study included almost twice as many female participants as male so the construct validity for men and women might be different. Another limitation is the limited diversity of the sample in terms of nationality as according Shkushkovnika Russians had higher anxiety level than Latvian population (Škuškovnika, 2004). Thus, future studies need to recruit larger samples of male participants to confirm the psychometric properties of the STAI in different genders and age groups.

\section{Conclusions}

The state and trait anxiety inventory scale showed promising evidence of reliability and validity for using in Latvian universities students sample. The analysis of situational anxiety data reveal the statistically significant differences between women and men irritability, anxiety and subjective self-perception $(p<.005)$. The data of anxiety as personality traits shows that men are much less worry about the things that really are not important than women. But for women unimportant thought runs through their minds more often than it comes to men $(\mathrm{p}<.005)$.

STAI-S structure distinguishes four factors: inner comfort, cognitive interpretation, internal discomfort and subjective perception of easiness. One component - ,confused" does not correlate with any factor $(n=318)$.

The STAI-T structure also distinguishes four factors: inner harmony, cognitive self-concept, feelings of happiness and rest. Three statements: make decisions easily, feel like failure, feel inadequate do not correlate with any factor $(n=318)$.

Managing emotions is an important psychological issue. Early detecting and proper handling of anxiety problems is a major challenge for improving mental health in student population. Using adequate research instruments could help to solve this problem. 


\section{SOCIETY. INTEGRATION. EDUCATION. Volume I}

\section{References}

Aktekin, M., Karamn, T., Senol, Y.Y., Erdam, S., Eregin, H., \& Akaydin, M. (2001). Anxiety, depression and stressful life events among medical students: A prospective study in Antalya, Turkey. Medical Education, 35(1), 12-17

Andrade, L., Gorenstein, C., Vieira Filho, A. H., Tung, T. C., \& Artes, R. (2001). Psychometric properties of the Portuguese version of the State-Trait Anxiety Inventory applied to college students: factor analysis and relation to the Beck Depression Inventory. Brazilian Journal Of Medical And Biological Research, 34(3), 367-374.

Bekker, M. H. J., \& van Mens-Verhulst, J. (2007). Anxiety disorders: Sex differences in prevalence, degree and background, but genderneutral treatment. Gender Medicine, 4(B), S178-S193.

Bieling PJ, Antony MM \& Swinson RP (1998). The State-Trait Anxiety Inventory, Trait version: structure and content reexamined. Behaviour Research and Therapy, 36: 777788.

Bouteyre, E., Maurel, M., \& Bernaud, J. (2007). Daily hassles and depressive symptoms among first year psychology students in France: the role of coping and social support. Stress \& Health: Journal Of The International Society For The Investigation Of Stress, 23(2), 93-99.

Dahlin, M., Joneborg, N., \& Runeson, B. (2005). Stress and depression among medical students: a cross-sectional study. Medical Education, 39(6), 594-604

Eisenberg, D., Gollust, S. E., Golberstein, E., \& Hefner, J. L. (2007). Prevalence and correlates of depression, anxiety, and suicidality among university students. The American Journal of Orthopsychiatry, 77(4), 534-542

Head, L.G., \& Lindsey, J. D. (1983). Anxiety and the university student: A brief review of the professional literature. College Studies Journal, 17, 176-182

Leary, M.R. (1991). Social anxiety, shyness and related constructs. In J. P. Robinson, P. R. Shaver, \& L. S. Wrightsman (Eds.), Measures of personality and social psychological attitudes. San Diego, CA: Academic Press. pp. 161-194.

Lindsey, C. (2014). Trait anxiety in college students: the role of the approval seeking schema and separation individuation. College Student Journal, 48(3), 407-418.

McKnight, J., \& McKnight, M. A. (2012). Gender and Anxiety: A Comparison of Student Anxiety Levels in Face-to-Face and Video Conferencing Courses. Creative Education, 3(01), 92.

Mundia, L. (2010). The prevalence of depression, anxiety and stress in Brunei preservice student teachers. The Internet Journal of Mental Health, 6

Peden, A.R., Hall, L.A., Rayens, M.K., \& Beebe, L. (2000). Negative thinking mediates the effects of self-esteem on depressive symptoms in college women. Nursing Research, 49(4), 201-207.

Škuškovnika D. (2004). Trauksme latviešiem un Latvijā dzīvojošiem krieviem: promocijas darba kopsavilkums. Rīga: LU, 24 lpp.

Spielberger C.D. (1983). Manual for the State-Trait Anxiety Inventory (Form Y). Mind Garden, Menlo Park, CA.

Spielberger, C. D. (1985). Assessment of state and trait anxiety: Conceptual and methodological issues. Southern Psychologist, 2(4), 6-16

Stein, M. B., \& Stein, D. J. (2008). Social anxiety disorder. The Lancet, 371(9618), 11151125.

Tyrer, P. (1999). Anxiety: A Multidisciplinary Review. World Scientific Publishing, River Edge, NJ. 
Wong, J. G. W. S., Cheung, E. P. T., Chan, K. K. C., Ma, K. K. M., \& Tang, S. W. (2006). Web-based survey of depression, anxiety and stress in first-year tertiary education students in Hong Kong. Australian and New Zealand Journal of Psychiatry, 40(9), $777-$ 782 